\title{
Hydrogen peroxide mediates hyperglycemia-induced invasive activity via ERK and p38 MAPK in human pancreatic cancer
}

\author{
Wei $\mathrm{Li}^{1, *}$, Zhenhua Ma ${ }^{1, *}$, Jiguang $\mathrm{Ma}^{2}$, Xuqi $\mathrm{Li}^{3}$, Qinhong $\mathrm{Xu}^{3}$, Wanxing Duan ${ }^{1}$, \\ Xin Chen ${ }^{1}$, Yunfu Lv ${ }^{4}$, Shuang Zhou ${ }^{5}$, Erxi Wu ${ }^{5}$, Qingyong Ma ${ }^{1}$, Xiongwei Huo ${ }^{3}$ \\ ${ }^{1}$ Department of Hepatobiliary Surgery, The First Affiliated Hospital of Xi'an Jiaotong University, Xi'an, 710061, China \\ ${ }^{2}$ Department of Oncology, The First Affiliated Hospital of Xi'an Jiaotong University, Xi'an, 710061, China \\ ${ }^{3}$ Department of General Surgery, The First Affiliated Hospital of Xi'an Jiaotong University, Xi'an, 710061, China \\ ${ }^{4}$ Department of General Surgery, People's Hospital of Hainan Province, Haikou, 570311, China \\ ${ }^{5}$ Department of Pharmaceutical Sciences, North Dakota State University, Fargo, 58108, ND, USA \\ *These authors have contributed equally to this work \\ Correspondence to: \\ Qingyong Ma, e-mail: qyma56@mail.xjtu.edu.cn \\ Xiongwei Huo, e-mail: doctorhuoxw@163.com \\ Keywords: diabetes, SOD2, hydrogen peroxide, MAPK pathway, pancreatic cancer invasion \\ Received: March 16, $2015 \quad$ Accepted: August 26, $2015 \quad$ Published: September 05, 2015
}

\section{ABSTRACT}

Diabetes mellitus and pancreatic cancer are intimately related, as approximately $85 \%$ of pancreatic cancer patients suffer from glucose intolerance or even diabetes. In this study, we evaluate the underlying mechanism by which hyperglycemia modulates the invasive potential of cancer cells and contributes to their enhanced metastatic behavior. Here we show that hyperglycemia increases the hydrogen peroxide $\left(\mathrm{H}_{2} \mathrm{O}_{2}\right)$ concentration through up-regulation of manganese superoxide dismutase (SOD2) expression, which further activates the ERK and p38 MAPK pathways, as well as the transcription factors NF-KB and AP-1, in a time-dependent manner. The invasion of pancreatic cancer cells resulting from the activation of the $\mathrm{H}_{2} \mathrm{O}_{2}$ / MAPK axis under high glucose conditions is effectively inhibited by PD 98059 (ERK inhibitor), SB 203580 (p38 MAPK inhibitor), polyethylene glycol-conjugated catalase (PEG-CAT), or the siRNA specific to SOD2. In addition, streptozotocin-treated diabetic nude mice exhibit a stronger tumor invasive ability in renal capsule xenografts which could be suppressed by PEG-CAT treatment. Furthermore, the integrated optical density (IOD) of SOD2 and UPA stainings is higher in the tumor tissues of pancreatic cancer patients with diabetes compared with pancreatic cancer patients with euglycemia. Taken together, our results demonstrate that hyperglycemia enhances cell invasive ability through the SOD2 $/ \mathrm{H}_{2} \mathrm{O}_{2} /$ MAPK axis in human pancreatic cancer. Thus, $\mathrm{SOD} 2 / \mathrm{H}_{2} \mathrm{O}_{2} / \mathrm{MAPK}$ axis may represent a promising therapeutic target for pancreatic cancer patients combined with diabetes mellitus.

\section{INTRODUCTION}

As the fourth leading cause of cancer death worldwide, pancreatic cancer (PC) is an aggressive malignant disease with dismal prognosis, partially due to the lack of early diagnosis and treatment options [1]. Although surgery remains the only way to cure this severe disease, more than $80 \%$ of patients cannot be considered for surgical resection at the time of initial diagnosis [2]. Even seemingly resectable PC often fails to be cured due to the systemic spread of the cancer that occurs before the operation [3]. Current treatments for inoperable patients are still limited to chemotherapy, radiation, or both [4]. Thus, more comprehensive and constructive therapeutic strategies are urgently needed.

Diabetes mellitus (DM) is one of the most common non-communicable diseases worldwide and it is likely the third modifiable risk factor for PC, after cigarette smoking and obesity [5]. Approximately $85 \%$ of patients diagnosed with PC have impaired glucose tolerance or even DM [6]. Clinical data have clearly indicated that patients with DM can aggravate the progression of PC. Patients with DM 
exhibit larger tumor sizes $(>3 \mathrm{~cm})$ and the existence of DM was reported to be independently associated with a reduced median survival [7]. Preoperative DM decreased both the rates of disease-free survival and overall survival for patients undergoing resection for PC [8]. Our own study demonstrated that DM enhances perineural invasion in PC patients and aggravates a poor prognosis [9]. However, little is known about the specific mechanism regarding the relationship between PC progression and DM.

Hyperglycemia, a typical characteristic of DM, not only induces the overproduction of reactive oxygen species (ROS), but also modulates anti-oxidative mechanisms, contributing to a pro-oxidant state [10-11]. ROS consists of a number of chemically reactive molecules derived from oxygen, including hydrogen peroxide $\left(\mathrm{H}_{2} \mathrm{O}_{2}\right)$. As a double-edged sword, excess ROS production can kill cancer cells, whereas sublethal concentrations of ROS can stimulate tumor progression by promoting cell proliferation, survival, invasion and metastasis [12]. Our previous studies showed that high glucose (HG) can be regarded as an accelerator to increase cell proliferation through enhanced epidermal growth factor (EGF)/EGFR signaling, and as a promoter to enhance the invasive ability of PC cells [13-14]. We reasoned that the effects of DM on PC may be attributed to the induction of ROS [14]. The main antioxidant enzymes include superoxide dismutase (SOD) in the cytosol (CuZnSOD, SOD1) and mitochondria (Mn-SOD, SOD2), which converts superoxide anion $\left(\mathrm{O}_{2}^{-}\right)$into $\mathrm{H}_{2} \mathrm{O}_{2}$, as well as catalase (CAT) and glutathione peroxidase (GPX), which catabolize $\mathrm{H}_{2} \mathrm{O}_{2}$ into water [15]. SOD can induce the migration and invasion of cancer cells via its metabolic product $\mathrm{H}_{2} \mathrm{O}_{2}$ [16-17]. Meanwhile, as an $\mathrm{H}_{2} \mathrm{O}_{2}$ scavenger, catalase inhibits ROS-mediated tumor metastasis [12].

It has been known that ROS triggers the signaling pathways (e.g., mitogen activated protein kinase [MAPK] pathway) involved in cell migration and metastasis [18]. ROS activates members of the MAPK family including the extracellular signal-regulated kinase (ERK), c-jun NH-2 terminal kinase (JNK) and p38 MAPK, resulting in regulation of the activities of transcription factors, such as activator protein-1 (AP-1) and nuclear factor kappa B (NF$\kappa \mathrm{B})$, which in turn modulate the expression of metastasisrelated factors, including matrix metalloproteinases (MMPs) and the urokinase plasminogen activator (uPA) system. The consequence of ROS/MAPK activation finally results in local tumor invasion and distant metastasis [19].

In the current study, we investigated the production of $\mathrm{H}_{2} \mathrm{O}_{2}$ and the activities of the cellular antioxidant enzymes in PC cells in response to $\mathrm{HG}$ treatments. We also tested the hypothesis that $\mathrm{H}_{2} \mathrm{O}_{2}$ mediates hyperglycemiainduced activation of the MAPK signaling pathways and regulates the invasive activity of PC cells. Our findings may provide new insight into the molecular interaction between HG levels and PC and reveal a novel therapeutic strategy for PC patients who suffer from diabetes.

\section{RESULTS}

\section{Effects of $\mathrm{HG}$ on $\mathrm{H}_{2} \mathrm{O}_{2}$ production and the expression of antioxidant enzymes in PC cells}

To explore the possible relationship between HG and oxidative stress, we first examined the effects of $\mathrm{HG}$ on $\mathrm{H}_{2} \mathrm{O}_{2}$ production in $\mathrm{PC}$ cells. Our results show that the levels of $\mathrm{H}_{2} \mathrm{O}_{2}$ in $\mathrm{BxPC}-3$ and Panc- 1 cells are upregulated in response to high glucose concentrations in comparison to normal physiological glucose level (5.5 $\mathrm{mM}$ glucose) in both time-dependent and dose-dependent manners. Additionally, the $\mathrm{HG}$-induced change in $\mathrm{H}_{2} \mathrm{O}_{2}$ production was not attributable to the osmolarity effects on the cancer cells because the addition of mannitol, an osmosis regulator, did not affect the level of $\mathrm{H}_{2} \mathrm{O}_{2}$ (Figure 1A).

Next, the protein expressions and activities of antioxidant enzymes in the PC cells exposed to HG were evaluated using Western blot analysis and antioxidant enzyme activity assay. As shown in Figure 1B, the protein levels of SOD2 and CAT were up-regulated in response to increasing concentrations of HG. However, the expression of SOD1 and GPX protein levels was not influenced by HG. Treatment with mannitol did not affect the expression of the antioxidant enzymes. HG condition could also influence the activity of the antioxidant enzymes SOD and CAT, and this trend was consistent with the results from the protein expression analysis (Figure 1C-1E). All of the tested antioxidant enzymes exhibited cytoplasmic localization in both the BxPC-3 and Panc-1 cancer cells (Supplementary Figures S1).

\section{SOD2 is involved in the HG-induced up-regulation of $\mathrm{H}_{2} \mathrm{O}_{2}$ production}

To further examine whether SOD2 could influence $\mathrm{H}_{2} \mathrm{O}_{2}$ production under $\mathrm{HG}$ conditions, we used SOD2 siRNA to knock down SOD2 expression in both BxPC-3 and Panc-1 cancer cells and then examined the $\mathrm{H}_{2} \mathrm{O}_{2}$ levels (Figure 1F, 1G). Our results show that the increased $\mathrm{H}_{2} \mathrm{O}_{2}$ production of the $\mathrm{PC}$ cells in the presence of $\mathrm{HG}$ was diminished when SOD2 was knocked down, indicating that the HG-induced $\mathrm{H}_{2} \mathrm{O}_{2}$ level is dependent on SOD2 (Figure 1H).

\section{HG activates the ERK and p38 MAPK signaling pathways via the production of $\mathrm{H}_{2} \mathrm{O}_{2}$}

To determine whether $\mathrm{HG}$ could influence the activation of MAPK signaling pathways, we analyzed the expression of ERK, p38 MAPK as well as the related transcription factors using Western blot analysis. As shown in Figure 2A, HG treatment induced the phosphorylation of ERK and p38 MAPK, as well as the phosphorylation of the transcription factors NF- $\kappa \mathrm{B}$ and $\mathrm{c}-\mathrm{Jun}$, in a 

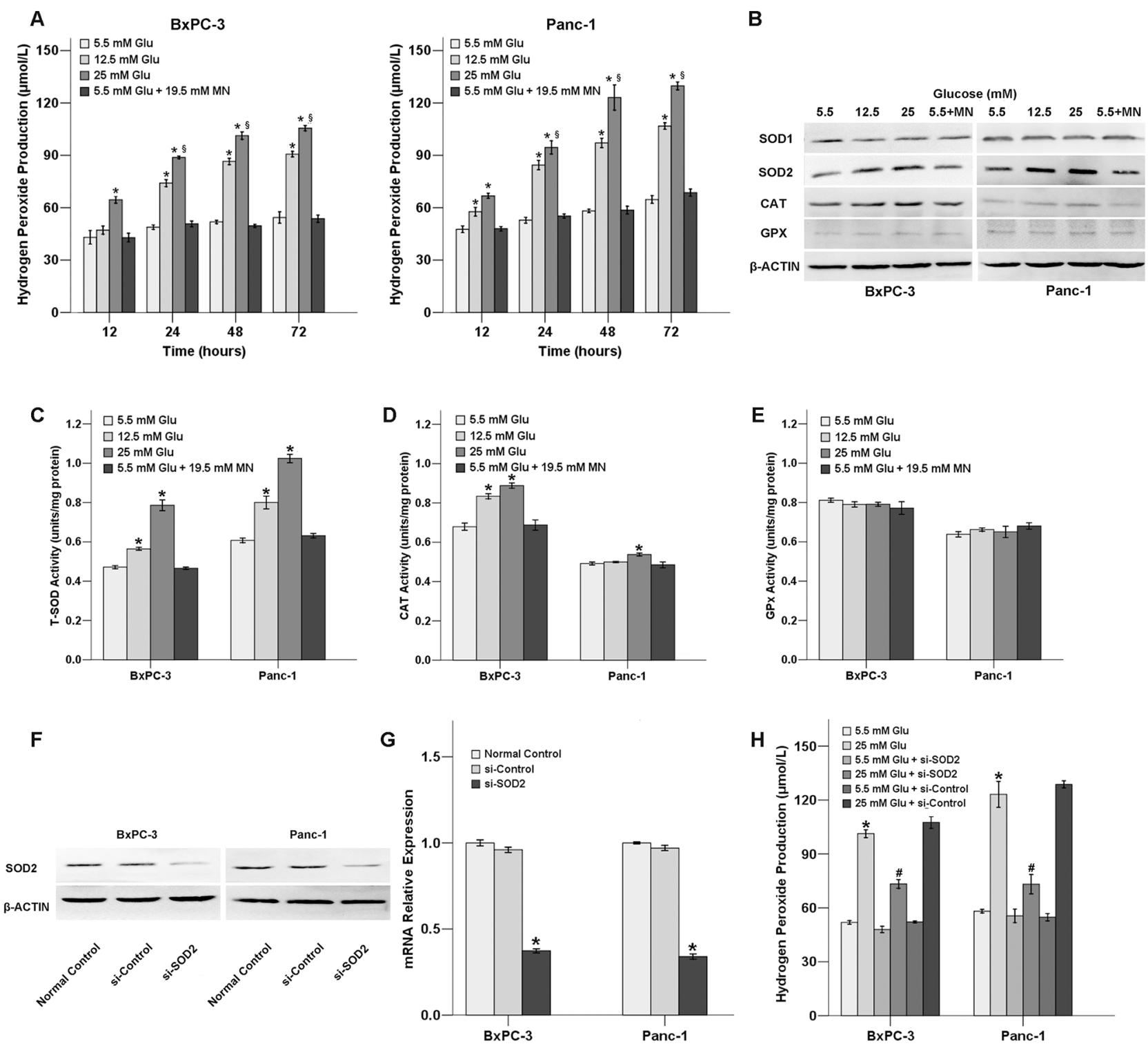

Figure 1: HG promotes the production of $\mathrm{H}_{2} \mathrm{O}_{2}$ via up-regulating SOD2 level. A. Hydrogen peroxide production of PC cells treated with HG. BxPC-3 and Panc-1 cells were treated with the indicated concentrations of HG $(5.5,12.5$, or $25 \mathrm{mM}$ or $5.5 \mathrm{mM} \mathrm{HG}+19.5$ $\mathrm{mM}$ mannitol), respectively, for $\mathrm{H}_{2} \mathrm{O}_{2}$ detection. B. The effect of glucose on the protein levels of antioxidant enzymes. Cancer cells were treated with different concentrations of glucose for $72 \mathrm{~h}$ to detect protein levels of antioxidant enzymes. C. The activity of the antioxidant enzymes T-SOD (total-SOD) in response to HG treatment for $72 \mathrm{~h}$. D. The activity of the antioxidant enzymes CAT in response to HG treatment for $72 \mathrm{~h}$. E. The activity of the antioxidant enzymes GPx in response to HG treatment for $72 \mathrm{~h}$. F. Knockdown of SOD2 by siRNA for $48 \mathrm{~h}$ was confirmed using Western blot analysis. G. Knockdown of SOD2 by siRNA for $48 \mathrm{~h}$ was confirmed using QT-PCR analysis. H. The $\mathrm{H}_{2} \mathrm{O}_{2}$ level was altered in response to SOD2 knockdown after $48 \mathrm{~h}$. The data are representative of 3 independent experiments. ${ }^{*} P<0.05$ compared to the $5.5 \mathrm{mM}$ glucose group; ${ }^{\circledR} P<0.05$ compared to the $25 \mathrm{mM}$ glucose group at $12 \mathrm{~h} ;{ }^{\#} P<0.05$ compared to the 25 $\mathrm{mM}$ glucose + si-control group.

time-dependent manner in the PC cells. The increased phosphorylation levels of ERK and p38 MAPK were detected after $1 \mathrm{~h}$ of stimulation with $\mathrm{HG}$ and remained at high levels until $24 \mathrm{~h}$, while the activation of $\mathrm{p}-\mathrm{NF}-\kappa \mathrm{B}$ and p-c-Jun began after $3 \mathrm{~h}$ of HG stimulation.

To investigate whether the activation of the MAPK signaling pathway was related with the production of $\mathrm{H}_{2} \mathrm{O}_{2}$, we directly treated BxPC-3 and Panc-1 cancer cells with $\mathrm{H}_{2} \mathrm{O}_{2}$. To determine the best intervention concentration of $\mathrm{H}_{2} \mathrm{O}_{2}$ to use on the PC cells, we cultured BxPC-3 and Panc-1 cells in media containing increasing concentrations $(0-800 \mu \mathrm{M})$ of $\mathrm{H}_{2} \mathrm{O}_{2}$ and the effects on cell proliferation were determined using an MTT assay. The results show that $\mathrm{H}_{2} \mathrm{O}_{2}$ induces cell proliferation in BxPC-3 cells in a dose-dependent manner after incubation for 24,48 , or $72 \mathrm{~h}$ with 0 to $200 \mu \mathrm{M} \mathrm{H}_{2} \mathrm{O}_{2}$; however, $\mathrm{H}_{2} \mathrm{O}_{2}$ was cytotoxic at concentrations above $200 \mu \mathrm{M}$. A similar effect of $\mathrm{H}_{2} \mathrm{O}_{2}$ was also observed in 
A

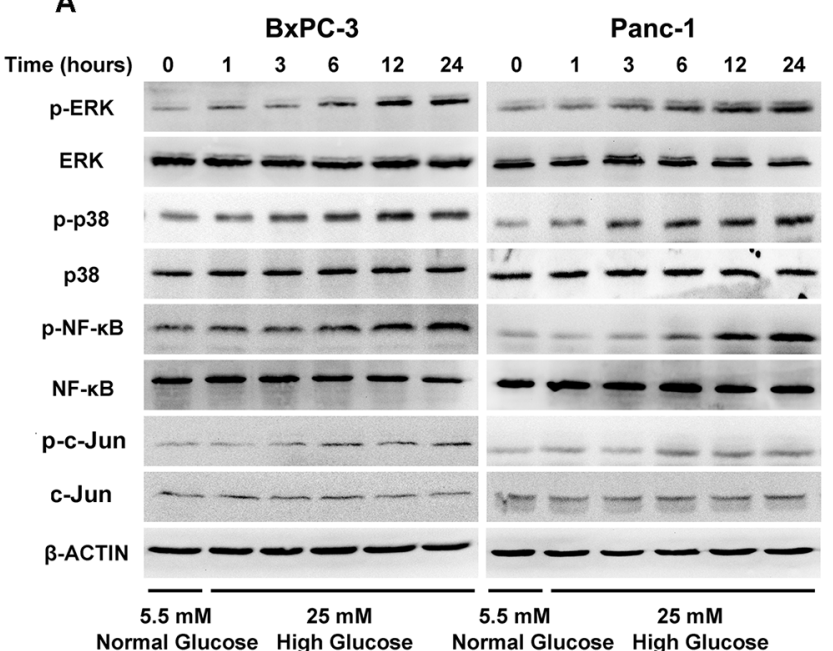

Normal Glucose High Glucose Normal Glucose High Glucose
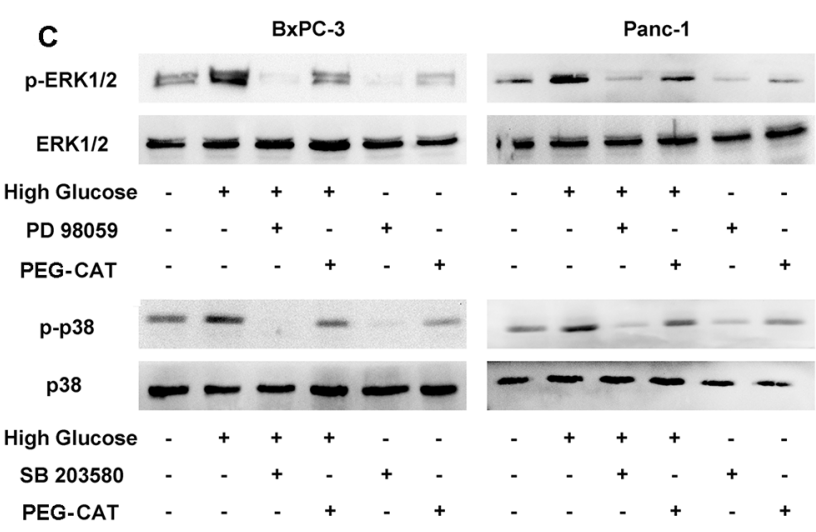

BxPC-3

Panc-1

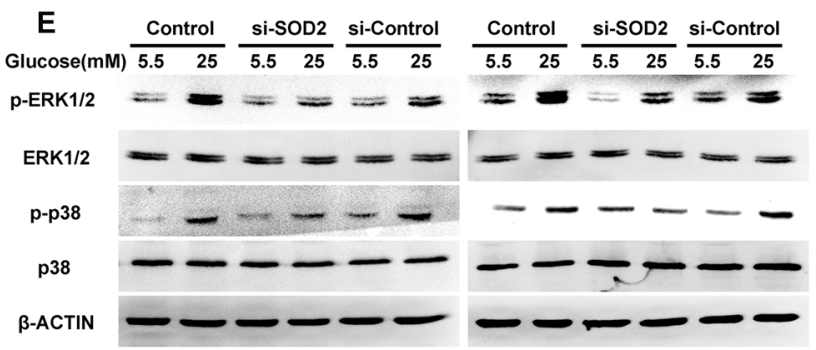

B

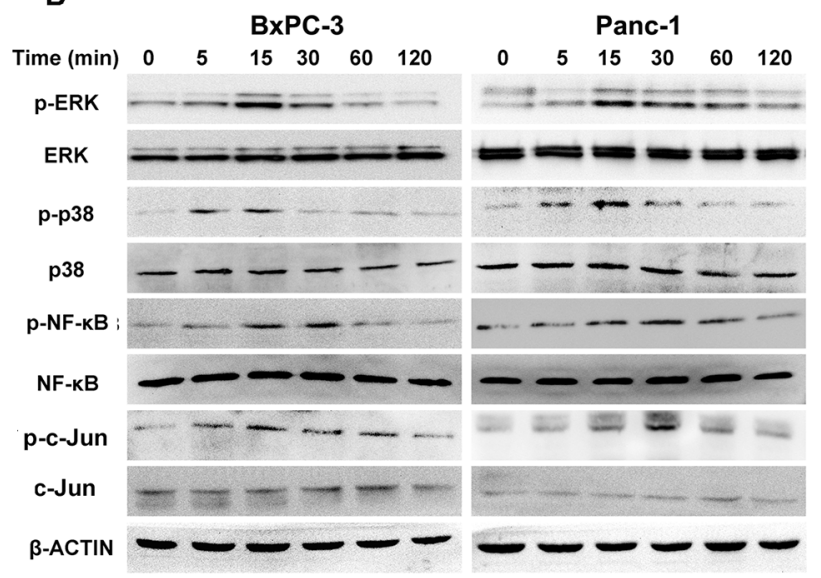

Hydrogen Peroxide (200 $\mu \mathrm{M})$

Hydrogen Peroxide (200 $\mu \mathrm{M})$

\section{D}
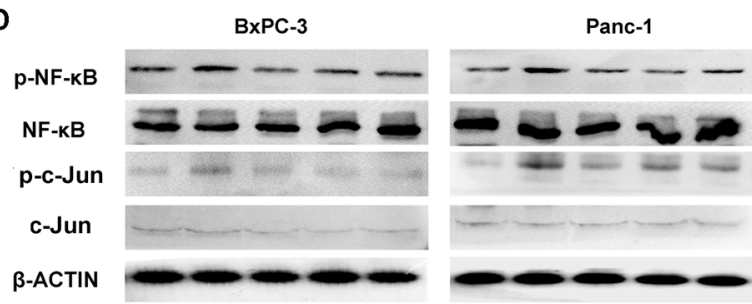

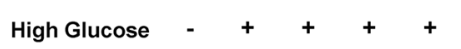

PD $98059 \quad-\quad-\quad+\quad-\quad-$

SB 203580

PEG-CAT

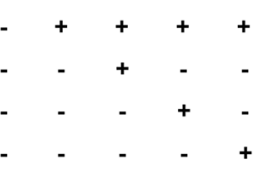

Panc-1

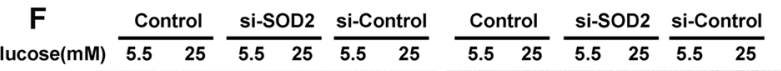

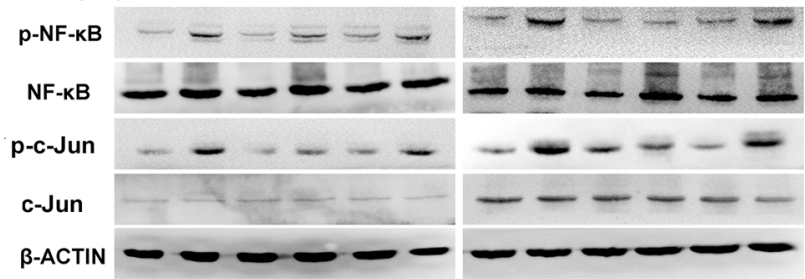

Figure 2: HG activates MAPK pathways and the NF- $\mathrm{BB}$ and AP-1 transcription factors via the production of $\mathrm{H}_{2} \mathrm{O}_{2}$ in BxPC-3 and Panc-1 cells. A. The effect of $25 \mathrm{mM}$ glucose on the phosphorylation of ERK, p38 MAPK, NF-kB and c-Jun. PC cells were treated with $25 \mathrm{mM}$ glucose for the indicated times. Phosphorylation of ERK, p38 MAPK, NF-kB and c-Jun were determined using Western blot analysis. B. The effect of $\mathrm{H}_{2} \mathrm{O}_{2}(200 \mu \mathrm{M})$ on the phosphorylation of ERK, p38 MAPK, NF-kB and c-Jun. PC cells were treated with $200 \mu \mathrm{M} \mathrm{H}_{2} \mathrm{O}_{2}$ for the indicated times. Phosphorylation of ERK, p38 MAPK, NF- $\mathrm{kB}$ and c-Jun were determined using Western blot analysis. C. The effect of MAPK pathway inhibitors on the phosphorylation of ERK and p38. D. The effect of MAPK pathway inhibitors on the phosphorylation of NF-kB and c-Jun. BxPC-3 and Panc-1 cells were treated with the selective MAPK pathway inhibitors PD $98059(50 \mu \mathrm{M})$ and SB $203580(20 \mu \mathrm{M})$, as well as PEG-CAT $(1000 \mathrm{U} / \mathrm{ml})$ in the presence or absence of high glucose concentrations. The phosphorylation of ERK, p38 (C), NF-kB and c-Jun (D) were analyzed using Western blot analysis for $24 \mathrm{~h}$. E. The effect of SOD2 knockdown on the phosphorylation of ERK and p38 in the presence or absence of high glucose concentrations. F. The effect of SOD2 knockdown on the phosphorylation of NF-kB and c-Jun in the presence or absence of high glucose concentrations. After the BxPC-3 and Panc-1 cells were transfected with siRNAs for $48 \mathrm{~h}$, the phosphorylation levels of ERK, p38 (E), NF-kB and c-Jun (F) were determined using Western blot analysis.

the Panc-1 cancer cells (Supplementary Figures S2A). Therefore, a treatment concentration of $200 \mu \mathrm{M} \mathrm{H}_{2} \mathrm{O}_{2}$ was used in the subsequent experiments. As shown in Figure $2 \mathrm{~B}, \mathrm{H}_{2} \mathrm{O}_{2}$ activated ERK and $\mathrm{p} 38$ MAPK in a time-dependent manner, with peak activation between 5 and $15 \mathrm{~min}$. Meanwhile, $\mathrm{H}_{2} \mathrm{O}_{2}$ treatment also led to an increase in the phosphorylation level of NF- $\mathrm{KB}$ and c-Jun, with a peak between 15 and 30 min. 
We next treated both BxPC-3 and Panc-1 cells with the ERK inhibitor, PD 98059, or the p38 MAPK inhibitor, SB 203580, and tested for the best intervention concentrations. The results demonstrate that both inhibitors suppress cells' proliferation in a concentration-dependent manner in both cell lines. For cells under treatment for $72 \mathrm{~h}$, the $\mathrm{IC}_{50}$ of PD 98059 in both PC cell lines was approximately $50 \mu \mathrm{M}$, whereas the $\mathrm{IC}_{50}$ of SB 203580 in BxPC-3 and Panc-1 cancer cells was approximately $20 \mu \mathrm{M}$ (Supplementary Figure S2B, S2C). To further assess whether the $\mathrm{HG}$-induced $\mathrm{H}_{2} \mathrm{O}_{2}$ production was involved in the MAPK activation, PC cells were treated with both $\mathrm{HG}$ and polyethylene glycol-conjugated catalase (PEG-CAT), which is able to prolong the circulatory half-life of the native CAT enzyme and enhances its intracellular access. Interestingly, we found that PEG-CAT diminished the HGinduced ERK and p38 MAPK phosphorylation (Figure 2C). Treating the PC cells with PEG-CAT and PD 98059 or SB 203580 also diminished the phosphorylation levels of NF$\kappa \mathrm{B}$ and c-Jun, indicating that $\mathrm{H}_{2} \mathrm{O}_{2}$ and the MAPK signaling pathway mediates the activation of these transcription factors (Figure 2D). Furthermore, as shown in Figure 2E, the phosphorylation levels of ERK and p38 MAPK were significantly decreased following SOD2 knockdown, indicating that the SOD2-induced $\mathrm{H}_{2} \mathrm{O}_{2}$ level is intimately related to the MAPK pathway. The phosphorylation levels of NF- $\kappa \mathrm{B}$ and c-Jun were also diminished in the si-SOD2 group (Figure 2F).

\section{$\mathrm{H}_{2} \mathrm{O}_{2}$ production is required for the $\mathrm{HG}$-induced up-regulation of uPA}

Our previous study demonstrated that HG could promote the invasive ability of PC cells through the upregulation of the metastasis-related factor uPA [14]. To examine whether the HG-induced uPA expression is related to the $\mathrm{H}_{2} \mathrm{O}_{2}$ level, $\mathrm{H}_{2} \mathrm{O}_{2}$, PEG-CAT and si-SOD2 were used to test the expression of uPA. As illustrated in Figure 3, the expression of UPA that is located in the cytoplasm (Figure 3A), was increased following the addition of $\mathrm{H}_{2} \mathrm{O}_{2}$ in a dose-dependent manner (Figure 3B). PEG-CAT cleared the produced $\mathrm{H}_{2} \mathrm{O}_{2}$, and si-SOD2 decreased the production of $\mathrm{H}_{2} \mathrm{O}_{2}$, both of PEG-CAT and si-SOD2 down-regulated the expression of uPA under $\mathrm{HG}$ conditions in PC cells (Figure 3C, 3D). In addition, both PD 98059 and SB 203580 could decrease the expression of UPA in PC cells under HG conditions, indicating that the activation of the ERK and p38 MAPK signaling pathway is involved in HG-induced uPA expression (Figure 3E).

\section{Increased $\mathrm{H}_{2} \mathrm{O}_{2}$ production and activation of the ERK and p38 MAPK signaling pathways are involved in HG-induced cell invasion}

To explore whether the $\mathrm{H}_{2} \mathrm{O}_{2}$ level is involved in the HG-induced cell invasive ability, PC cells were treated with $\mathrm{H}_{2} \mathrm{O}_{2}$, PEG-CAT, and si-SOD2, and the invasive abilities of the cells were examined under different glucose conditions. The results show that both $\mathrm{HG}$ and $\mathrm{H}_{2} \mathrm{O}_{2}$ increased the invasion rates of cancer cells. $\mathrm{HG}$-induced cell invasion decreased when $\mathrm{H}_{2} \mathrm{O}_{2}$ was eliminated by either PEG-CAT or si-SOD2 treatment (Figure 4). Furthermore, both PD 98059 and SB 203580 could decrease PC cells invasion under HG conditions, indicating that the activation of the ERK and p38 MAPK signaling pathways is involved in $\mathrm{HG}$-induced PC cell invasion (Figure 5).

\section{PEG-CAT inhibits tumor invasion in streptozotocin (STZ)-treated nude mice}

To determine the efficacy of different drugs against transplantation-established human tumor xenografts in the athymic nude mice, we used a subrenal capsular assay. STZ is a chemical which is commonly used to induce experimental diabetes in animals [20]. The characteristics of the STZ-treated nude mice used in this study were summarized in Figure 6. The fasting blood glucose levels were significantly increased from 2 weeks to 4 weeks after STZ injection (Figure 6A) and the body weight of the nude mice was reduced at 4 weeks after STZ injection (Figure 6B).

In the subrenal capsular assay, cancer cells were maintained in a discrete, solid structure under the kidney capsule and were able to invade into the kidney parenchyma, identified by detection of the tumor cells surrounding renal glomeruli and tubules. As shown by the $\mathrm{H} \& \mathrm{E}$ staining results in Figure 6C, the invasive ability of both the BxPC-3 and Panc-1 cells were strongly enhanced in the DM renal capsule xenograft model and this increase could be suppressed by PEG-CAT treatment. Taken together, these results indicate that the hyperglycemiainduced increase of the level of $\mathrm{H}_{2} \mathrm{O}_{2}$ is involved in the acceleration of tumor invasion.

\section{The expression of SOD1, SOD2, and uPA in pancreatic ductal carcinoma specimens}

Of all 417 cases, 149 (35.73\%) had hyperglycemia (new-onset diabetes and uncontrolled diabetes). The remaining 268 cases (euglycemia group) included controlled diabetic or non-diabetic cases. The hyperglycemia and euglycemia groups were similar in terms of age, sex, and body mass index (BMI). Among the 149 hyperglycemia cases, 47 had a history of diabetes, compared with 14 of 268 euglycemia cases $(P<0.001$, Chi-square test).

We further investigated the change in the expression levels of the SOD and uPA in human PC specimen in the euglycemia and hyperglycemia groups. As shown in Figure 7, the majority of SOD1, SOD2, and uPA staining was located at the cytoplasm. There is 
A
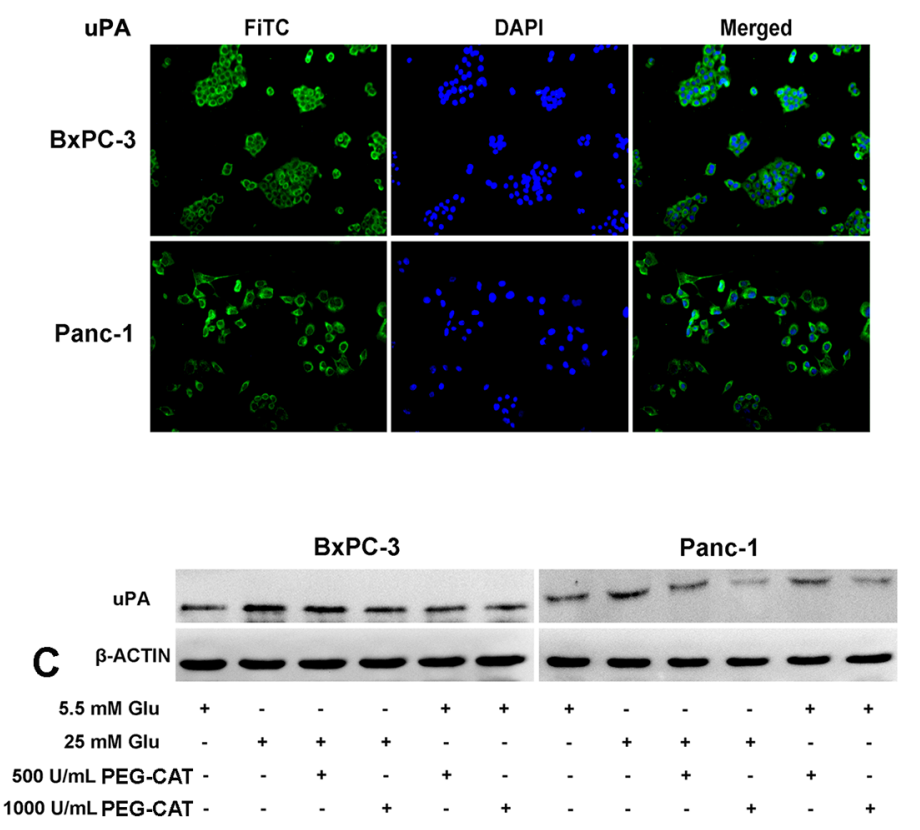

$\mathbf{E}$

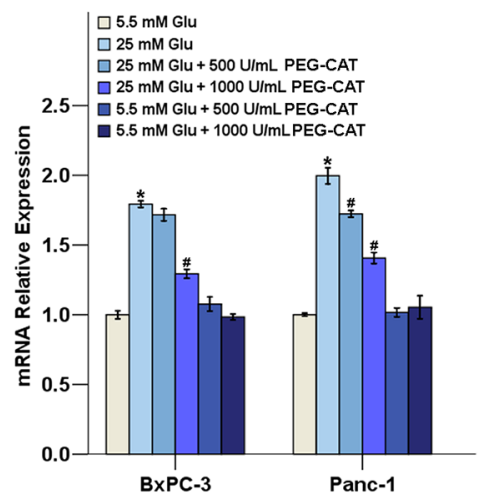

BXPC-3 Panc-1

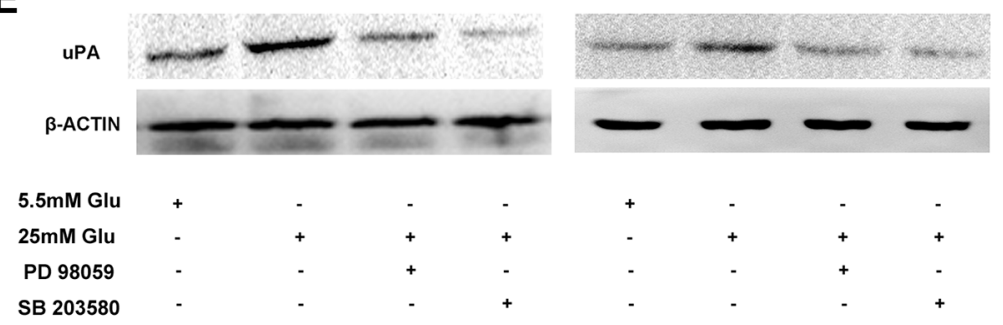

Hydrogen Peroxide ( $\mu \mathrm{mol} / \mathrm{L})$
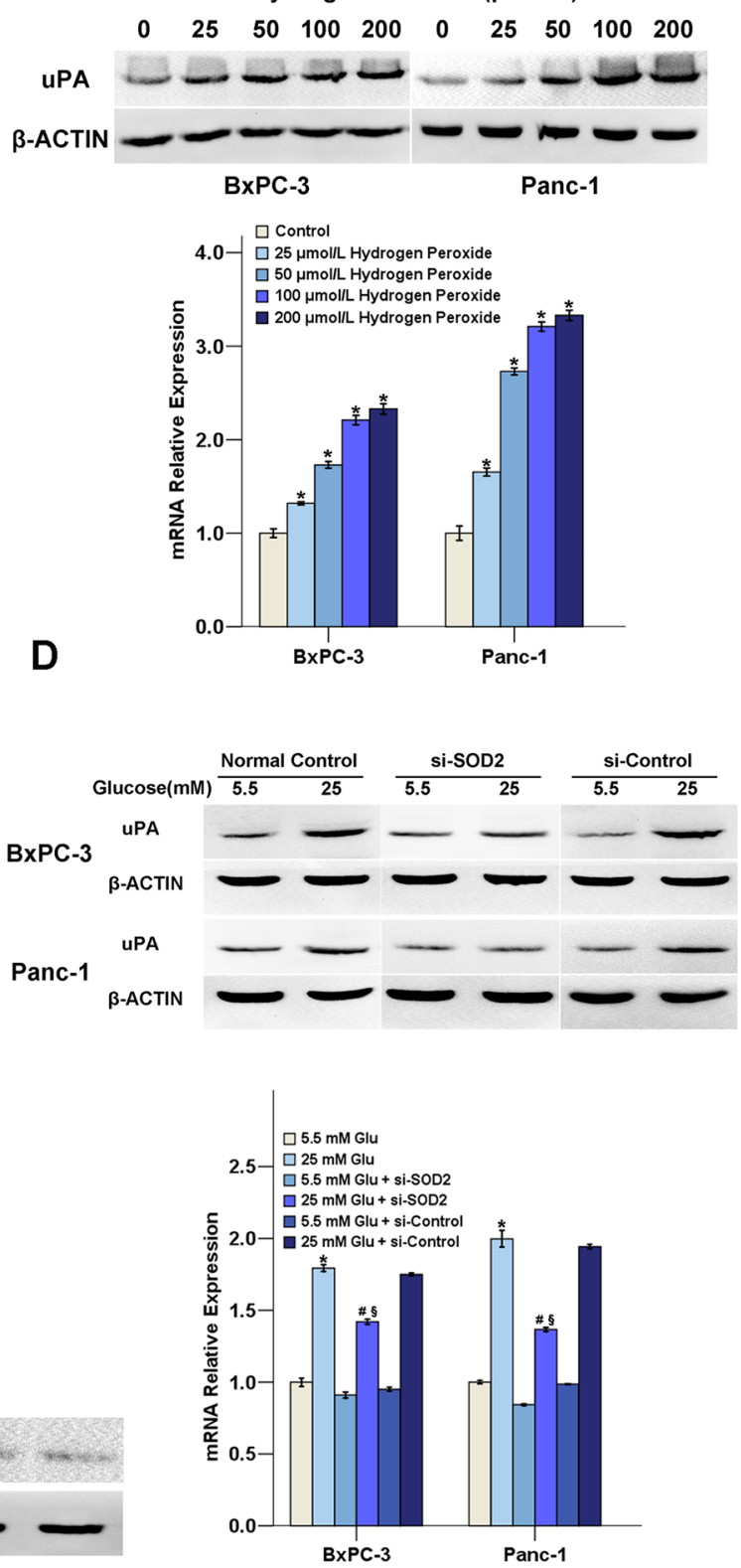

Figure 3: Effect of $\mathrm{H}_{2} \mathrm{O}_{2}$ on uPA expression. A. The subcellular localization of uPA. PC cells were labeled with a fluorescenceconjugated uPA specific antibody (green) $(\times 200)$. The nuclei were stained with DAPI. uPA was localized exclusively in the cytoplasm. B. BxPC-3 and Panc-1 cells were treated with different concentrations of $\mathrm{H}_{2} \mathrm{O}_{2}(0,25,50,100$ or $200 \mu \mathrm{M})$ for $48 \mathrm{~h}$ for mRNA and protein detection. C. The regulation on uPA expression in response to PEG-CAT treatment (500 or $1000 \mathrm{U} / \mathrm{ml})$. D. The regulation on uPA expression in response to SOD2 knockdown. E. The regulatioin on uPA expression in response to and MAPK pathway inhibitors. The data are representative of 3 independent experiments. ${ }^{*} P<0.05$ compared to the $5.5 \mathrm{mM}$ glucose group; ${ }^{\sharp} P<0.05$ compared to the $25 \mathrm{mM}$ glucose group; ${ }^{\S} P<0.05$ compared to the $25 \mathrm{mM}$ glucose + si-control group.

a decreased staining intensity of SOD1 and SOD2 in PC specimens when compared with normal pancreas. Little or no uPA immunoreactivity was observed in normal pancreatic tissues. The SOD2 and uPA stainings in the cytoplasm of the cancer cells was significantly stronger in the hyperglycemia group than in the euglycemia group, indicating that hyperglycemia is able to increase the expression of SOD2 and uPA protein levels. The 

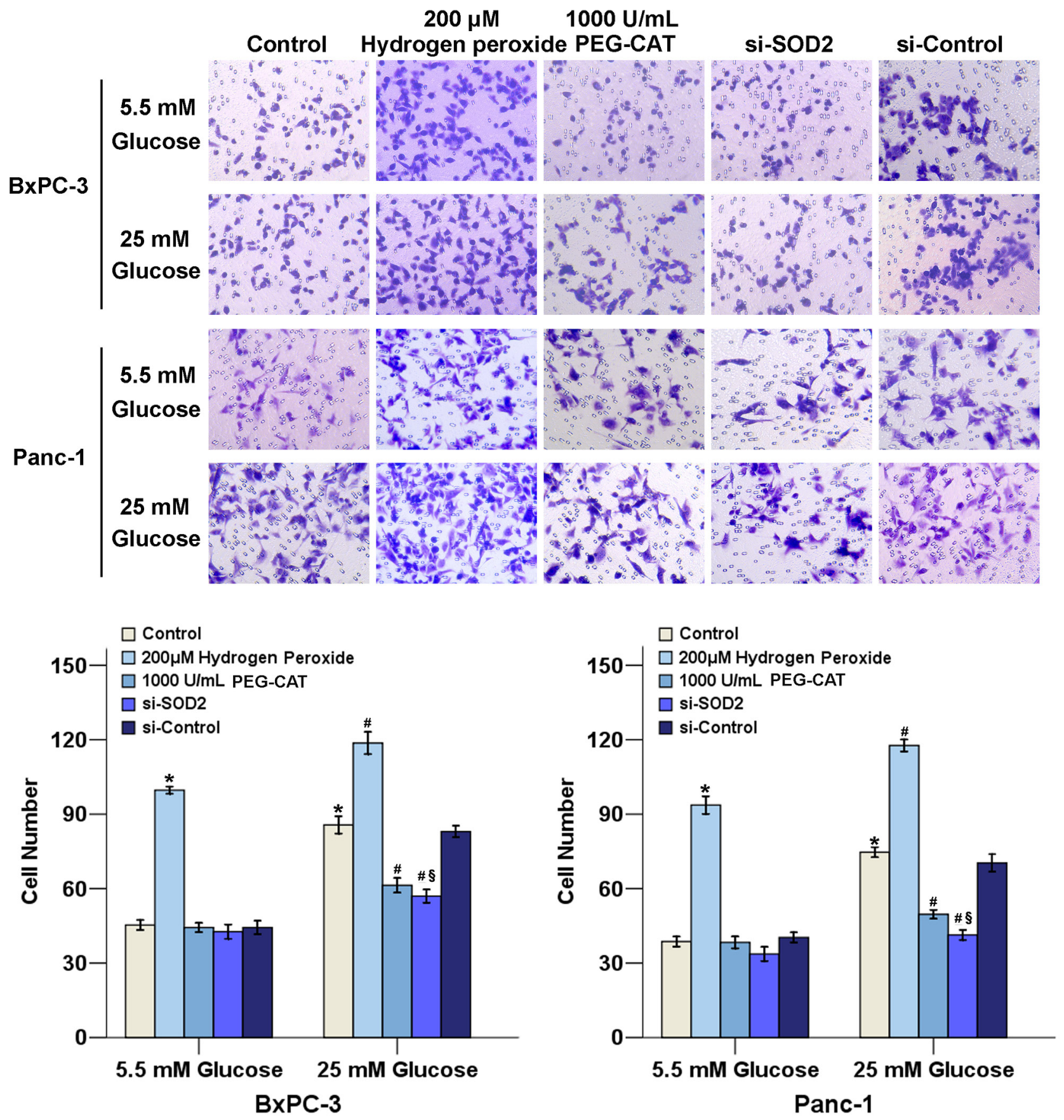

Figure 4: The effect of $\mathrm{H}_{2} \mathrm{O}_{2}$ on the cancer cell's invasive ability under HG conditions. PC cells in DMEM medium containing $1 \%$ FBS were seeded in the matrigel-coated Transwell upper chambers. 20\% FBS was used as chemoattractant. Cancer cells were treated with $200 \mu \mathrm{M} \mathrm{H}_{2} \mathrm{O}_{2}, 1000 \mathrm{U} / \mathrm{L}$ PEG-CAT or si-SOD2 in the presence or absence of high glucose concentrations. After $48 \mathrm{~h}$, the cells on the upper surface of the filters were removed; the filters were then stained with crystal violet. The number of migrated cells was quantified by counting the cells from 10 random fields at $\times 200$ magnification. The data are representative of 3 independent experiments. ${ }^{*} P<0.05$ compared to the $5.5 \mathrm{mM}$ glucose group; ${ }^{\#} P<0.05$ compared to the $25 \mathrm{mM}$ glucose group, ${ }^{\S} P<0.05$ compared to the $25 \mathrm{mM}$ glucose + si-control group.

percentage of positive SOD2 and uPA staining cancer cells were significantly higher in the hyperglycemia group than in the euglycemia group. However, there was little difference in SOD1 expression between hyperglycemia group and euglycemia group.

\section{DISCUSSION}

Due to the high rate of locally deteriorated or metastatic disease at the time of diagnosis and the lack of effective medical therapy, PC has been considered one 

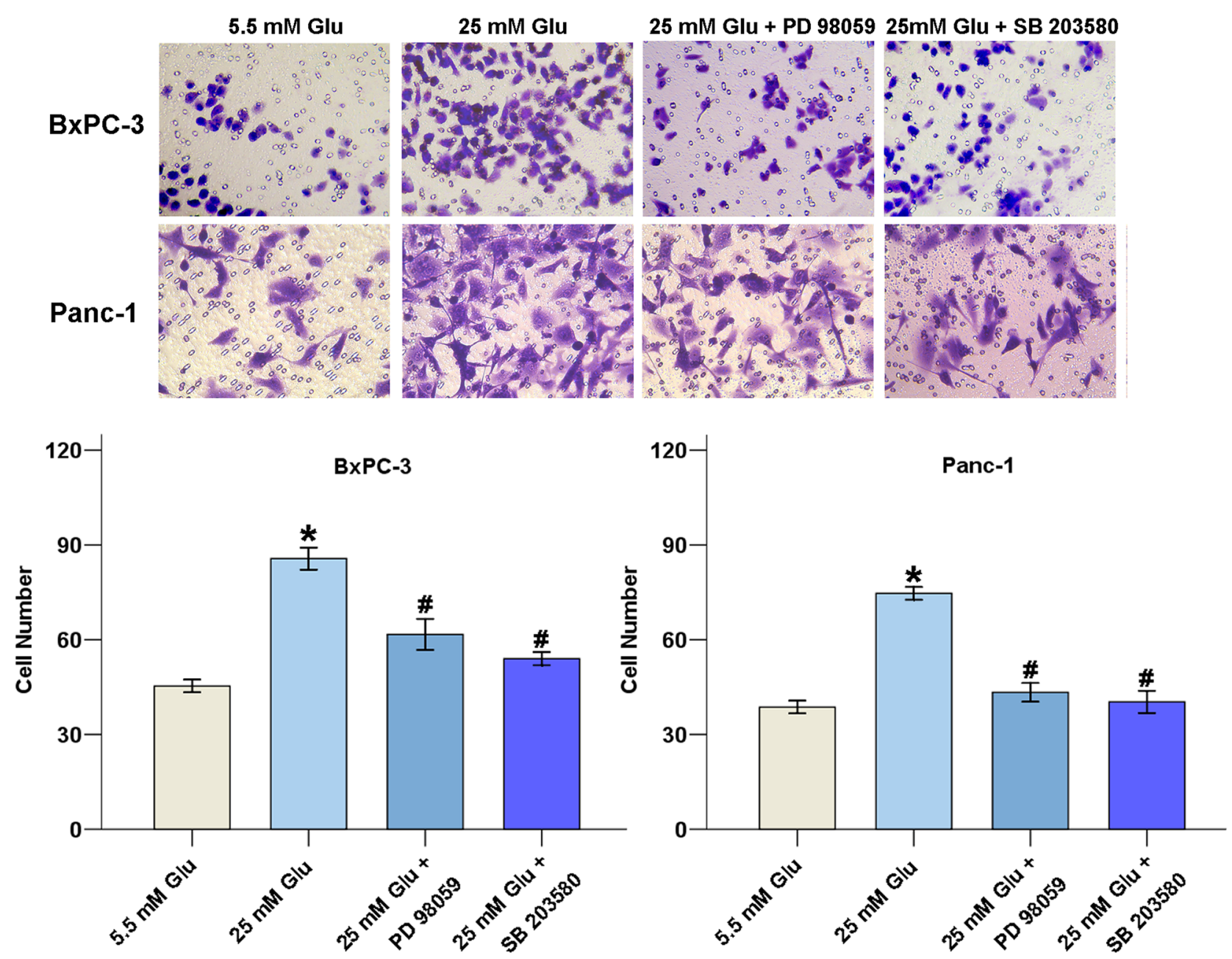

Figure 5: MAPK activation modulates PC progression. BxPC-3 and Panc-1 cells were exposed to the MAPK pathway inhibitors PD $98059(50 \mu \mathrm{M})$ and SB $203580(20 \mu \mathrm{M})$ for $48 \mathrm{~h}$, the number of migrated cells was quantified by counting the number of cells from 10 random fields at $\times 200$ magnification. The data are representative of 3 independent experiments. $* P<0.05$ compared to the $5.5 \mathrm{mM}$ glucose group; ${ }^{\#} P<0.05$ compared to the $25 \mathrm{mM}$ glucose group.

of the most lethal malignant diseases. In recent years, although the largest improvements in survival have been made for a number of other cancers, PC still shows the least improvement [1]. It has been estimated that the mortality rates of cancers of the lung, colon, breast and prostate will decline due to the combined effects of widespread screening, smoking cessation and more effective therapy, and PC may become the leading cause of cancer-related deaths in the USA by 2050 [21]. Therefore, the exploration of risk factors, metastatic mechanisms and therapeutic targets for PC has become hot topics in recent years.

$\mathrm{DM}$, which is a very common metabolic disorder characterized by hyperglycemia that eventually affects all of the systems in the body, has been postulated to be both an independent risk factor and a consequence for $\mathrm{PC}$ in recent years [22]. On one hand, a large number of epidemiological studies have demonstrated that DM increases an individual's risk of developing PC [23] and anti-diabetic drugs can be used to prevent and treat PC
[24]. On the other hand, DM may be a consequence of $\mathrm{PC}$ because there is an increased prevalence of diabetes in PC patients and DM may be resolved after surgery (pancreaticoduodenectomy) [25]. However, little is known about the specific mechanism underlying this linkage.

Our data show that the hyperglycemia-induced invasive ability of PC cells could be attributed to the production of ROS. There are 6 major pathways that contribute to the production of ROS under HG conditions: glyceraldehyde autoxidation, PKC activation, glycation, sorbitol metabolism, the hexosamine pathway, and oxidative phosphorylation [26]. ROS can be considered as a double-edged sword in cancer cells; excess ROS production can kill cells, whereas sublethal concentrations of ROS can promote cell progression [12]. Our results indicate that high glucose resulted in an increase in the level of $\mathrm{H}_{2} \mathrm{O}_{2}$ to a non-toxic level in PC cells; treatment with $\mathrm{H}_{2} \mathrm{O}_{2}$ promoted cancer cell proliferation when its concentration was below $200 \mu \mathrm{M}$, but $\mathrm{H}_{2} \mathrm{O}_{2}$ concentrations 
A

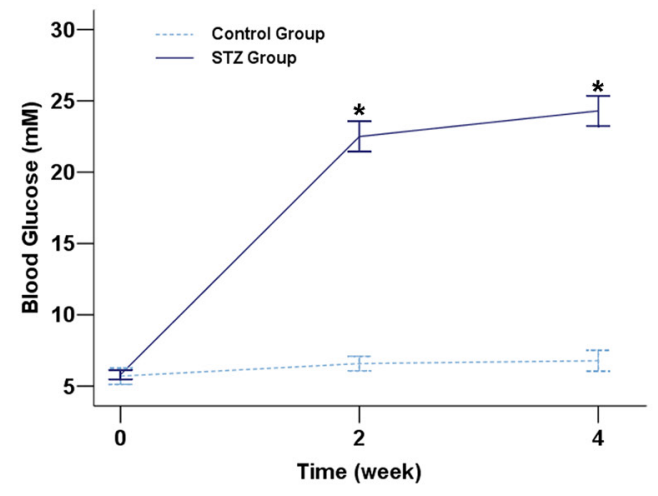

C

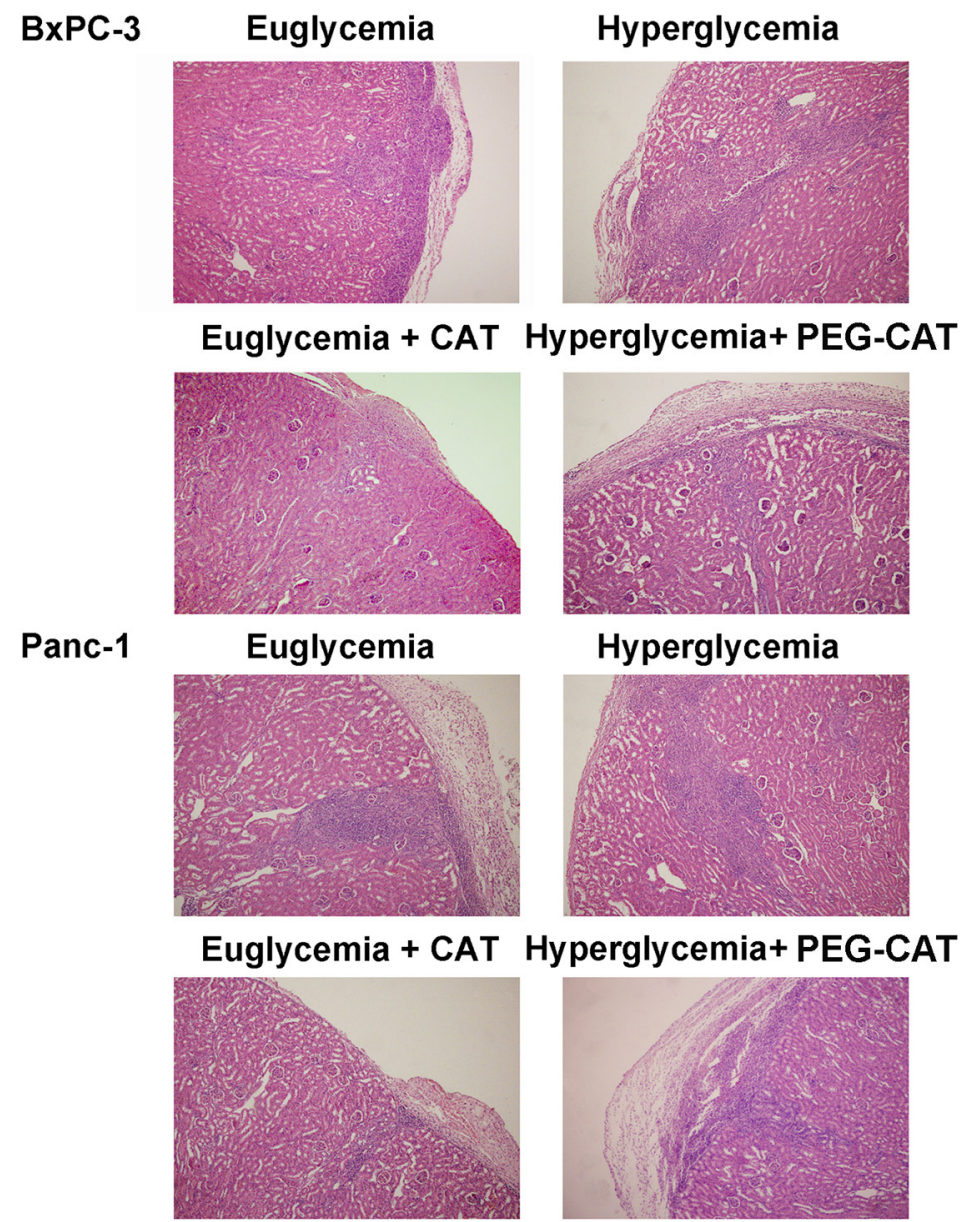

B

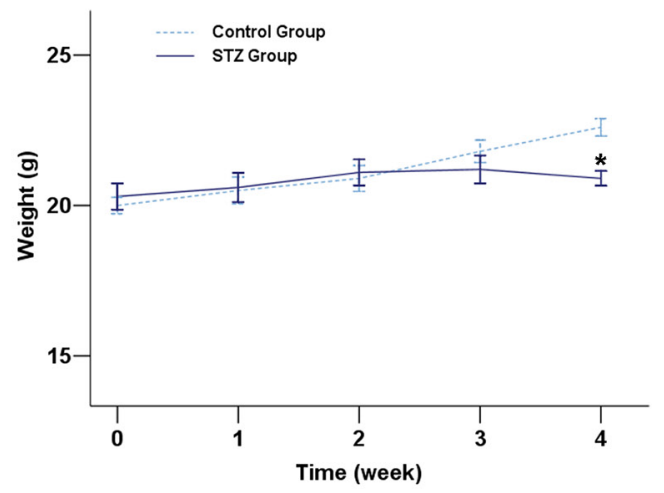

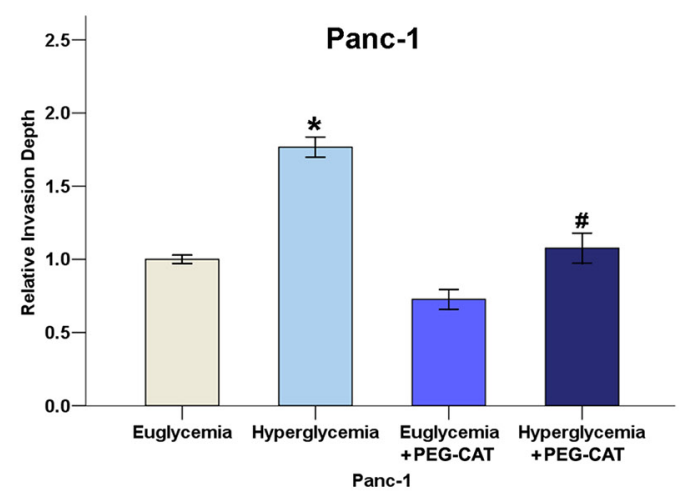

Figure 6: Effect of the hyperglycemia/ $\mathrm{H}_{2} \mathrm{O}_{2}$ axis on the invasion of $\mathrm{PC}$ in nude mice. A. Blood glucose in STZ-treated mice $(n=12)$. B. Body weight in STZ-treated mice $(n=12)$. C. The H\&E staining results showed that the invasion ability of the PC cells was enhanced in the renal capsule xenografts of the hyperglycemic mice and this increase could be strongly suppressed by repeated injections of PEG-CAT. ${ }^{*} P<0.05$ compared to euglycemia group; ${ }^{*} P<0.05$ compared to hyperglycemia group.

above $200 \mu \mathrm{M}$ were toxic to the cancer cells. Recently, Ikemura et al. [27] showed that there were larger and more tumor metastatic colonies in the lung and liver of the STZ-treated mice and injections of PEG-CAT could effectively inhibit tumor metastasis. They concluded that the increased oxidative stress, not a high blood glucose level, could accelerate tumor metastasis in hyperglycemic mice. Additionally, the hyperglycemia-induced increase in ROS also resulted in the up-regulation of adhesion molecules expression, through which tumor cells adhere to endothelial cells to form metastatic colonies [28-29]. $\mathrm{H}_{2} \mathrm{O}_{2}$ is diffusible and thus capable of traveling across plasma membranes into the extracellular space to exert both paracrine and autocrine roles. In our in vitro study, we observed that $\mathrm{H}_{2} \mathrm{O}_{2}$ could increase the invasive ability of the PC cells, whereas treatment with either PEG-CAT, 

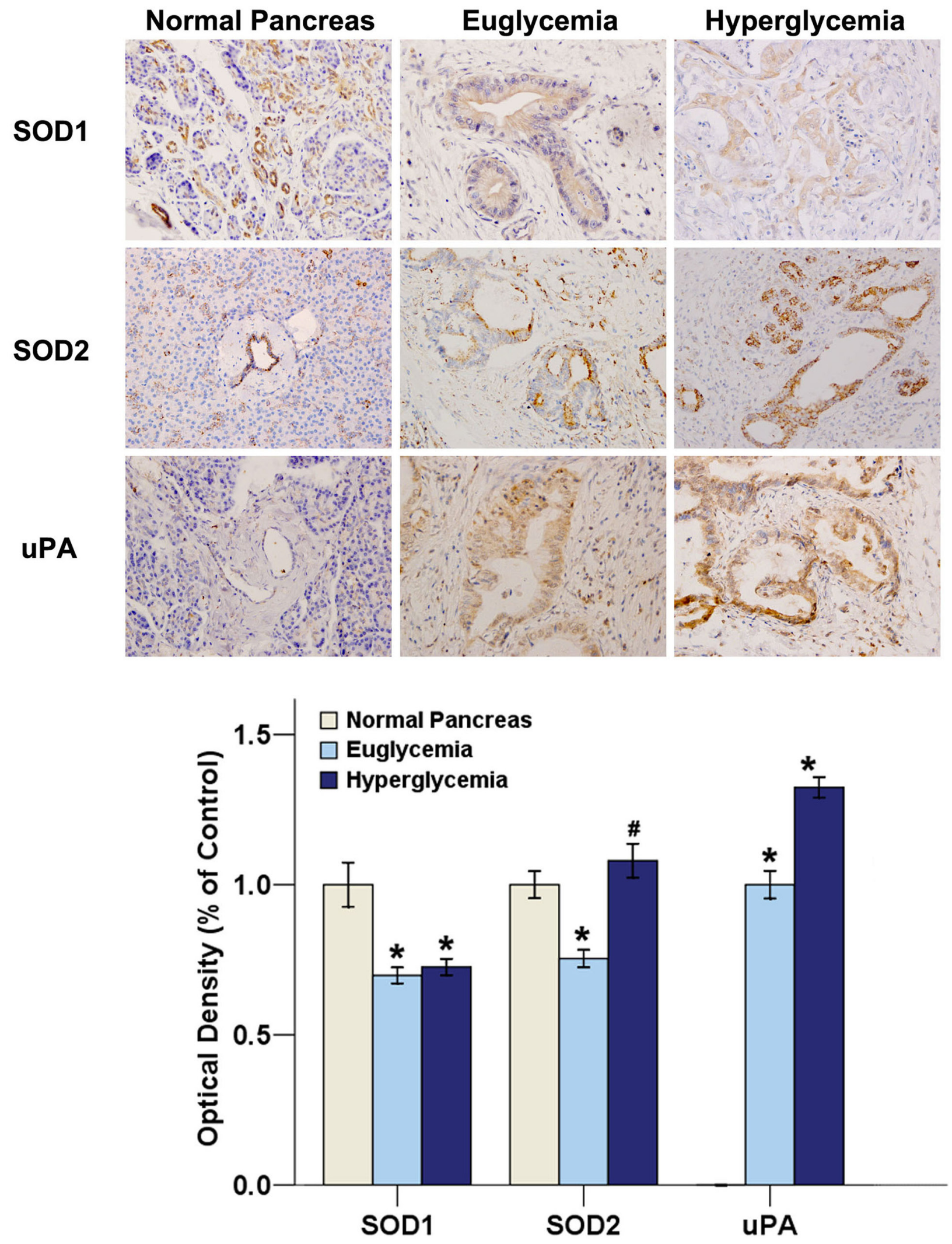

Figure 7: Hyperglycemia promotes SOD2 and uPA expressions in human PC tissues. Sixty-five patients (19 specimens in the hyperglycemia group and 46 specimens in the euglycemia group) who received a radical curative pancreatic operation with a pathologic diagnosis and 8 normal pancreases were investigated. The SOD1, SOD2 and uPA immuno-stainings were analyzed by Image-Pro Plus software. Original magnification $\times 400$. ${ }^{*} P<0.05$ as compared with normal pancreas group. ${ }^{\sharp} P<0.05$ as compared with euglycemia group. 
which cleared the produced $\mathrm{H}_{2} \mathrm{O}_{2}$, or si-SOD2, which decreased the production of $\mathrm{H}_{2} \mathrm{O}_{2}$, could terminate this effect. Additionally, in our in vivo study, we demonstrated that a single injection of STZ could lead to a reduction in body weight and an increase in the fasting blood glucose level of nude mouse. Hyperglycemic conditions enhanced the invasive ability of both BxPC-3 and Panc-1 cells in renal capsule xenografts and this effect might be attributed to the production of $\mathrm{H}_{2} \mathrm{O}_{2}$, as injection of PEGCAT effectively inhibited tumor invasion in the STZtreated mice. In addition, hyperglycemia is correlated with increased expression levels of SOD2 and UPA in the tissue specimens obtained from PC patients. As our previous study demonstrated that DM enhances perineural invasion in $\mathrm{PC}$ patients [9], we assumed that this enhancement might be related with $\mathrm{HG}$-induced $\mathrm{H}_{2} \mathrm{O}_{2}$ production.

Cellular SOD converts intracellular superoxide radicals into $\mathrm{H}_{2} \mathrm{O}_{2}$ that is cleared by GPX and CAT and converted into water. It has been shown that the SOD activity was much higher in both diabetic patients [30-31] and STZtreated/alloxan-induced diabetic mice compared to those with normal blood glucose [20,32]. SODs are a family of antioxidant enzymes responsible for the detoxification of superoxide anion. SOD1 is located in the cytoplasm, while SOD2 is in the mitochondria [15]. In the current study, we found that $\mathrm{HG}$ increases SOD2, but not SOD1 expression, which might indicate that hyperglycemia preferentially affect $\mathrm{H}_{2} \mathrm{O}_{2}$ production in mitochondria. In addition, we also showed that $\mathrm{SOD}$-induced $\mathrm{H}_{2} \mathrm{O}_{2}$ production promoted tumor cell invasion; while si-SOD2 and PEG-CAT treatment inhibits these effects. In recent years, increased SOD2 levels have been associated with poor prognosis and resistance to therapy of several tumors in the central nervous system, gastrointestinal tract, head and neck [33]. Toh et al. [34] reported 2.19- and 3.72-fold increases in SOD2 mRNA expression relative to normal tissue in gastric and colorectal cancers, respectively. Lewis et al. [35] indicated that nude mice that were injected with human PC cells occasionally developed intra-abdominal metastatic deposits and ascites that were associated with an increase in SOD2 activity. The A allele of the SOD2 - 1221G > A genotype was associated with a higher risk of pancreatic cancer among individuals with a low dietary vitamin E intake [36]. However, there are also many reports that SOD2 has characteristics of tumor suppressor and can inhibit cancer development and progression [37]. Hempel et al. [38] concluded that there is a dichotomous role for SOD2 during tumorigenisis. SOD2 may act as a tumor suppressor during the initial onset/proliferative stage of tumor initiation, yet once the tumor progresses to a more aggressive and invasive phenotype, SOD2 levels appear to positively correlate and contribute to enhanced metastatic behavior of cancer cells. Our results support the concept that metastatic disease is associated with changes in the content and activity of the antioxidant enzymes [35]. Additionally, In agreement with other reports [31-39], the activity of CAT was also found to be slightly increased under HG conditions. This may be attributed to the fact that persistent hyperglycemia leads to increased $\mathrm{H}_{2} \mathrm{O}_{2}$ levels, which eventually results in the induction of CAT activity.

The MAPK signaling pathways are important signaling cascades downstream of ROS that are involved in tumor migration and invasion [18]. Cheng et al. [40] observed that $\mathrm{H}_{2} \mathrm{O}_{2}$ is a mediator of the epidermal growth factor (EGF)-mediated activation of the p38 MAPK pathway and cell invasion in ovarian cancer cells. Lee et al. [41] also showed that hepatocyte growth factor (HGF) regulates $\mathrm{H}_{2} \mathrm{O}_{2}$ production which further activates the ERK pathway and regulates uPA production, eventually increasing the invasive potential of stomach cancer cells. Our results show that HG could promote the activation of p-ERK, p-p38, p-NF- $\mathrm{kB}$ and p-c-Jun via $\mathrm{H}_{2} \mathrm{O}_{2}$. After suppressing the MAPK signaling pathway by treatment with PD 98059 or SB 203580, the invasive ability of PC cells decreased. Additionally, the down-regulation of $\mathrm{H}_{2} \mathrm{O}_{2}$ by either PEG-CAT or si-SOD2 inhibits the activation of the MAPK signaling pathways and tumor invasion, which indicates that $\mathrm{H}_{2} \mathrm{O}_{2}$ is the key factor that mediated $\mathrm{HG}$-induced PC metastasis.

\section{MATERIALS AND METHODS}

The study protocol and consent forms conform to the Declaration of Helsinki and were approved by the Ethical Review Board (ERB) Committee (The First Affiliated Hospital of Medical College, Xi'an Jiaotong University, China) and the written informed consent was obtained from all participants.

\section{Collection of tissues and immunohistochemistry}

From January 2007 to July 2014, 520 pancreatic tumors were subjected to clinical examination at the First Affiliated Hospital, Xi'an Jiaotong University, China. Among them, 417 cases were diagnosed with pancreatic ductal carcinoma excluding islet cell carcinoma, intraductal papillary mucinous tumor and acinar cell carcinoma. The 417 pancreatic tumors were divided into two groups according to their fasting blood glucose levels (an average long-term glucose level for patients with a history of diabetes mellitus and an average three-day glucose level after hospitalization): (1) euglycemia or normal (no diabetic or controlled diabetic cases) and (2) hyperglycemia or high (new-onset diabetes and uncontrolled diabetes). Most PC patients were diagnosed at the advanced-stage and not suitable for surgical resection. Therefore, only sixty-five patients who received a radical curative pancreatic operation with a pathologic diagnosis and 8 normal pancreases (also from the First Affiliated Hospital, Xi'an Jiaotong University) were included in this study. Formalin fixed and paraffin embedded PC tissue samples from the above fiftynine patients were used for the immunohistochemistry test.

The tissue sections were incubated with primary antibodies (anti-SOD1, anti-SOD2 and anti-uPA, 1:50) 
overnight at $4{ }^{\circ} \mathrm{C}$ and incubated with the appropriate biotinylated secondary antibody for $30 \mathrm{~min}$ at room temperature. After rinsing, the results were visualized using diaminobenzidine (DAB) and the slides were counterstained with hematoxylin. The densitometry analysis of immunohistochemical staining was performed using the Image-Pro Plus 6.0 software.

\section{Cell culture and reagents}

The human PC cell lines, BxPC-3 and Panc-1, were obtained from the American Type Culture Collection (Manassas, VA, USA). The cells were cultured in Dulbecco's Modified Eagle's Medium (DMEM) supplemented with $10 \%$ dialyzed heat-inactivated fetal bovine serum, $100 \mathrm{U} /$ $\mathrm{ml}$ penicillin and $100 \mu \mathrm{g} / \mathrm{ml}$ streptomycin in a $95 \%$ air $/ 5 \%$ $\mathrm{CO}_{2}$ humidified atmosphere at $37^{\circ} \mathrm{C}$. Catalase derivative conjugated to polyethylene glycol (PEG-catalase) and streptozotocin (STZ) were acquired from Sigma Aldrich (St. Louis, MO, USA). The ERK inhibitor PD 98059 and the p38 MAPK inhibitor SB 203580 were obtained from Sigma Chemical Co. Primary antibodies against SOD1, SOD2, CAT, GPX1 and uPA were procured from Santa Cruz Biotechnology (Santa Cruz, CA, USA). The antiERK, anti-phospho-ERK (Thr202/Tyr204), anti-p38 MAPK, anti-phospho-p38 MAPK (Thr180/Tyr182), anti-

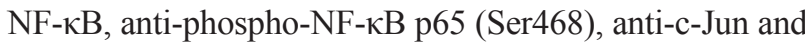
anti-phospho-c-Jun (Ser63) antibodies were obtained from Cell Signaling Technology (Beverly, MA, USA).

\section{Hydrogen peroxide assay}

The level of intracellular $\mathrm{H}_{2} \mathrm{O}_{2}$ was measured using hydrogen peroxide assay kit according to the manufacturer's instructions. In this kit, the ferrous ions $\mathrm{Fe}^{2+}$ were oxidized to ferric ions $\mathrm{Fe}^{3+}$ by $\mathrm{H}_{2} \mathrm{O}_{2}$. The ferric ions further formed a complex with the indicator dye xylenol orange and produced a visible purple-colored complex that could then be measured using a microplate reader at a wavelength of 560-590 nm (Bio-Rad, CA, USA).

\section{Antioxidant enzyme activities}

The bioactivity of SOD was measured using a total SOD activity assay kit (Beyotime, Jinan, China). This assay is based on the ability of SOD to inhibit the formation of water-soluble formazan dye that results from the reaction between superoxide anion and WST-1. The absorbance at a wavelength of $450 \mathrm{~nm}$ was measured using a microplate reader. The activity of total SOD was calculated according to the manufacturer's instructions.

The CAT activity was detected using a catalase analysis kit (Beyotime, Jinan, China). Briefly, the cell lysates were treated with excess $\mathrm{H}_{2} \mathrm{O}_{2}$ that was decomposed by CAT for the indicated times. Afterwards, the remaining $\mathrm{H}_{2} \mathrm{O}_{2}$ was coupled to a substrate and was catalyzed by peroxidase to generate the red product that could be detected using a microplate reader at a wavelength of $520 \mathrm{~nm}$. Catalase activity was then calculated from the assay results.

The activity of GPX was examined using a total glutathione peroxidase assay kit (Beyotime, Jinan, China). Briefly, GPX was indirectly measured by evaluating the level of NADPH oxidation in a coupled assay system, containing glutathione, glutathione reductase and cumene hydroperoxide as the substrate, using a microplate reader at a wavelength of $340 \mathrm{~nm}$. GPX (1 unit) was defined as the amount of enzyme that oxidized $1 \mathrm{nmol}$ of NADPH in one minute.

\section{MTT assay}

BxPC-3 and Panc-1 cells were seeded in 96-well plates at a density of 5,000 to 10,000 cells per well and were incubated overnight in medium containing $10 \% \mathrm{FBS}$. The cells were then treated with increasing concentrations of PD 98059, SB 203580, or $\mathrm{H}_{2} \mathrm{O}_{2}$. After incubation for 24,48 , or $72 \mathrm{~h}$ at $37^{\circ} \mathrm{C}$, the MTT reagent was added to each well and was incubated at $37^{\circ} \mathrm{C}$ for $4 \mathrm{~h}$. DMSO was then added to each well and the optical density (OD) value at $490 \mathrm{~nm}$ was determined using a spectrophotometer (Bio-Rad, CA, USA). The results are presented as the percentages relative to the controls. The proliferation rate was defined as $=\mathrm{OD}_{\text {sample }} / \mathrm{OD}_{\text {control }} \times 100 \%$.

\section{Transwell matrigel invasion assay}

The invasive ability of the PC cells was analyzed using matrigel invasion chambers. The $8.0 \mu \mathrm{m}$ pore inserts were coated with $30 \mu \mathrm{l}$ of matrigel. Cell suspensions $\left(5 \times 10^{4}\right)$ were added to the upper chambers in DMEM containing $1 \%$ FBS. $500 \mu \mathrm{l}$ of DMEM containing 20\% FBS was placed in the lower chambers. The matrigel invasion chamber was then incubated for $48 \mathrm{~h}$ in a humidified tissue culture incubator. The non-invading cells were removed from the upper surface by scraping with a wet cotton swab. After rinsing with PBS, the filter was fixed and stained with crystal violet. The invasion ability was determined by counting the stained cells on the bottom surface.

\section{Real-time quantitative PCR (QT-PCR)}

Total RNA was extracted from the PC cells using the Fastgen200 RNA isolation system (Fastgen, Shanghai, China). Total RNA was reverse-transcribed into cDNA using the PrimeScript RT reagent Kit (TaKaRa, Dalian, China). The PCR reactions consisted of $30 \mathrm{~s}$ at $95^{\circ} \mathrm{C}$, followed by 40 cycles of $95^{\circ} \mathrm{C}$ for $5 \mathrm{~s}, 60^{\circ} \mathrm{C}$ for $30 \mathrm{~s}$ and $72^{\circ} \mathrm{C}$ for $30 \mathrm{~s}$. The relative gene expression was calculated using the previously described $2^{-\Delta \Delta C t}$ method [42]. The primer sequences were as follows:

SOD2-F: 5'-CAC CAC AGC AAG CAC CAC-3'. SOD2-R: 5'-GTT CTC CAC CAC CGT TAG G-3'. 
uPA-F: 5'- TAA GAG CTG GTG TCT GAT TG-3'. uPA-R: 5'- TTG GAT GAA CTA GGC TAAAA-3'. TTC T- $3^{\prime}$.

$\beta$-actin-F: 5'-GAC TTA GTT GCG TTA CAC CCT

$\beta$-actin-R: 5'- GAA CGG TGA AGG TGA CAG

CAG T $-3^{\prime}$.

\section{Western blot analysis}

Proteins were electrophoretically resolved on a denaturing SDS-polyacrylamide gel and were electrotransferred onto polyvinylidene difluoride membranes. The membranes were initially blocked with $5 \%$ nonfat dry milk in Tris-buffered saline (TBS) for $2 \mathrm{~h}$ and then probed with each primary antibody. After co-incubation with the primary antibodies at $4{ }^{\circ} \mathrm{C}$ overnight, the membranes were blotted with the secondary antibody for $2 \mathrm{~h}$ at $37^{\circ} \mathrm{C}$. The results were visualized using the ECL Western blotting substrate and were photographed by GeneBox (SynGene).

\section{RNAi transfections}

siRNA against SOD2 (SOD2-Homo-429: 5'-GGU GGU CAU AUC AAU CAU ATT-3', 5'-UAU GAU UGA UAU GAC CAC CTT-3') and a negative control siRNA (NC: $5^{\prime}$-UUC UCC GAA CGU GUC ACG UTT3', 5'-ACG UGA CAC GUU CGG AGA ATT-3') were purchased from GenePharm (Shanghai, China).

\section{Subrenal capsular assay and histopathology}

Five week old $\mathrm{BALB} / \mathrm{c}$ athymic nude mice were purchased from Shanghai Experimental Animal Center. Animal care and experiments were carried out in accordance with the guidelines of Institutional Animal Care and Use Committee at Xi'an Jiaotong University. For DM group, $\mathrm{BALB} / \mathrm{c}$ athymic nude mice received an intraperitoneal injection of STZ at a dose of $175 \mathrm{mg} / \mathrm{kg}$ body weight.

The subrenal capsular assay, a rapid in vivo test system for observing tumor proliferation and invasion, was established to test the efficacy of different drugs against transplantation-established human tumor xenografts in the athymic nude mice ( $n \geq 6$ for each group).

Two weeks after STZ injection, each mouse was used for the subrenal capsule assay. The BxPC-3 and Panc- 1 cell lines were used to create xenografts in the athymic nude mice. After anesthetization, the left kidney of each mouse was exposed and the same number of cells $\left(1 \times 10^{8}\right)$ was injected under the left renal capsule in a total volume of 25 (1. Three days later, PEG-CAT was intraperitoneally injected into a group of mice at a dose of 1000 units/d. The cells maintained a discrete, solid structure under the kidney capsule, and 3-dimensional growth was observed microscopically and directly quantified by changes in the average diameter. After inoculation with the tumor cells, the mice were sacrificed on day 14 and their left kidneys were excised.
The left renal capsule, as well as the xenografts, were fixed in $10 \%$ neutral buffered formalin and were processed in paraffin. Sections were cut using a microtome and were mounted on glass slides. After dewaxing, the sections were hydrated in graded alcoholic solutions and distilled water. Routine H\&E staining was performed.

\section{Statistical analysis}

Statistical analyses were performed using SPSS software (version 17.0, SPSS Inc., Chicago, USA). Data were presented as the means \pm SEM of three replicate assays. Differences between the groups were analyzed by analysis of variance (ANOVA). Statistical significance was set at $P<0.05$. All experiments were repeated independently at least three times.

\section{CONCLUSION}

The current study demonstrates that $\mathrm{H}_{2} \mathrm{O}_{2}$ contributes to the SOD2-induced invasion in PC cells in vitro by modulating the expression of the metastasis-related factor uPA through the activation of the ERK and p38 MAPK signaling pathways. This study also provides evidence that accelerated tumor invasion in hyperglycemic nude mice is due to the increased production of $\mathrm{H}_{2} \mathrm{O}_{2}$, which can be effectively inhibited by repeated injections of PEG-CAT. In addition, hyperglycemia is correlated with increased expression levels of SOD2 and uPA in the tissue specimens obtained from PC patients. These findings suggest that blocking the $\mathrm{SOD} 2 / \mathrm{H}_{2} \mathrm{O}_{2} / \mathrm{MAPK}$ signaling system may provide a novel strategy for the treatment of PC accompanied by DM.

\section{ACKNOWLEDGMENTS}

This study was supported by grants from National Natural Science Foundation of China (Grant serial numbers: 81301846 and 81472248 . We wish to extend our thanks to Dr. Lei Cao (Xi'an Jiaotong University) for her thoughtful reading of the manuscript.

\section{CONFLICTS OF INTEREST}

The authors declare that they have no competing interests.

\section{REFERENCES}

1. Siegel RL, Miller KD, Jemal A. Cancer statistics, 2015. CA Cancer J Clin. 2015; 65:5-29.

2. Wray CJ, Ahmad SA, Matthews JB, Lowy AM. Surgery for pancreatic cancer: recent controversies and current practice. Gastroenterology. 2005; 128:1626-1641. 
3. Castellanos EH, Cardin DB, Berlin JD. Treatment of earlystage pancreatic cancer. Oncology (Williston Park). 2011; 25:182-189.

4. Campen CJ, Dragovich T, Baker AF. Management strategies in pancreatic cancer. Am J Health Syst Pharm. 2011; 68:573-584.

5. Li D. Diabetes and pancreatic cancer. Mol Carcinog. 2012; 51:64-74.

6. Pannala R, Basu A, Petersen GM, Chari ST. New-onset diabetes: a potential clue to the early diagnosis of pancreatic cancer. Lancet Oncol. 2009; 10:88-95.

7. Chu CK, Mazo AE, Goodman M, Egnatashvili V, Sarmiento JM, Staley CA, Galloway JR, Adsay NV, Jacobs S, Kooby DA. Preoperative diabetes mellitus and long-term survival after resection of pancreatic adenocarcinoma. Ann Surg Oncol. 2010; 17:502-513.

8. Cannon RM, LeGrand R, Chagpar RB, Ahmad SA, McClaine R, Kim HJ, Rupp C, Cho CS, Brinkman A, Weber S, Winslow ER, Kooby DA, Chu CK, Staley CA, Glenn I, Hawkins WG, Parikh AA, Merchant NB, McMasters KM, Martin RC, Callender GG, Scoggins CR. Multi-institutional analysis of pancreatic adenocarcinoma demonstrating the effect of diabetes status on survival after resection. HPB (Oxford). 2012; 14:228-235.

9. Li J, Ma Q, Liu H, Guo K, Li F, Li W, Han L, Wang F, Wu E. Relationship between neural alteration and perineural invasion in pancreatic cancer patients with hyperglycemia. Plos One. 2011; 6:e17385.

10. Perez-Matute P, Zulet MA, Martinez JA. Reactive species and diabetes: counteracting oxidative stress to improve health. Curr Opin Pharmacol. 2009; 9:771-779.

11. Robertson RP. Chronic oxidative stress as a central mechanism for glucose toxicity in pancreatic islet beta cells in diabetes. J Biol Chem. 2004; 279:42351-42354.

12. Nishikawa M, Hashida M, Takakura Y. Catalase delivery for inhibiting ROS-mediated tissue injury and tumor metastasis. Adv Drug Deliv Rev. 2009; 61:319-326.

13. Han L, Ma Q, Li J, Liu H, Li W, Ma G, Xu Q, Zhou S, Wu E. High glucose promotes pancreatic cancer cell proliferation via the induction of EGF expression and transactivation of Egfr. Plos One. 2011; 6:e27074.

14. Li W, Ma Q, Li J, Guo K, Liu H, Han L, Ma G. Hyperglycemia enhances the invasive and migratory activity of pancreatic cancer cells via hydrogen peroxide. Oncol Rep. 2011; 25:1279-1287.

15. Liou GY, Storz P. Reactive oxygen species in cancer. Free Radic Res. 2010; 44:479-496.

16. Li F, Wang H, Huang C, Lin J, Zhu G, Hu R, Feng H. Hydrogen peroxide contributes to the manganese superoxide dismutase promotion of migration and invasion in glioma cells. Free Radic Res. 2011; 45:1154-1161.

17. Liu Z, Li S, Cai Y, Wang A, He Q, Zheng C, Zhao T, Ding X, Zhou X. Manganese superoxide dismutase induces migration and invasion of tongue squamous cell carcinoma via
$\mathrm{H}_{2} \mathrm{O}_{2}$-dependent Snail signaling. Free Radic Biol Med. 2012; 53:44-50.

18. Wu WS, Wu JR, Hu CT. Signal cross talks for sustained MAPK activation and cell migration: the potential role of reactive oxygen species. Cancer Metastasis Rev. 2008; 27:303-314

19. Tochhawng L, Deng S, Pervaiz S, Yap CT. Redox regulation of cancer cell migration and invasion. Mitochondrion. 2013; 13:246-253.

20. Jang YY, Song JH, Shin YK, Han ES, Lee CS. Protective effect of boldine on oxidative mitochondrial damage in streptozotocin-induced diabetic rats. Pharmacol Res. 2000; 42:361-371.

21. Siegel R, Naishadham D, Jemal A. Cancer statistics, 2012. CA Cancer J Clin. 2012; 62:10-29.

22. Cui Y, Andersen DK. Diabetes and pancreatic cancer. Endocr Relat Cancer. 2012; 19:F9-F26.

23. Ben Q, Xu M, Ning X, Liu J, Hong S, Huang W, Zhang H, Li Z. Diabetes mellitus and risk of pancreatic cancer: A meta-analysis of cohort studies. Eur J Cancer. 2011; 47:1928-1937.

24. Li W, Ma Q, Liu J, Han L, Ma G, Liu H, Shan T, Xie $\mathrm{K}, \mathrm{Wu}$ E. Hyperglycemia as a mechanism of pancreatic cancer metastasis. Front Biosci (Landmark ED). 2012; 17:1761-1774.

25. Wu JM, Kuo TC, Yang CY, Chiang PY, Jeng YM, Huang PH, Tien YW. Resolution of diabetes after pancreaticoduodenectomy in patients with and without pancreatic ductal cell adenocarcinoma. Ann Surg Oncol. 2013; 20:242-249.

26. Robertson R, Zhou H, Zhang T, Harmon JS. Chronic oxidative stress as a mechanism for glucose toxicity of the beta cell in type 2 diabetes. Cell Biochem Biophys. 2007; 48:139-146.

27. Ikemura M, Nishikawa M, Kusamori K, Fukuoka M, Yamashita F, Hashida M. Pivotal role of oxidative stress in tumor metastasis under diabetic conditions in mice. $\mathrm{J}$ Control Release. 2013; 170:191-197.

28. Hirano Y, Sakurai E, Matsubara A, Ogura Y. Suppression of ICAM-1 in retinal and choroidal endothelial cells by plasmid small-interfering RNAs in vivo. Invest Ophthalmol Vis Sci. 2010; 51:508-515.

29. Hyoudou K, Nishikawa M, Kobayashi Y, Kuramoto Y, Yamashita F, Hashida M. Inhibition of adhesion and proliferation of peritoneally disseminated tumor cells by pegylated catalase. Clin Exp Metastasis. 2006; 23:269-278.

30. Bandeira Sde M, Guedes Gda S, da Fonseca LJ, Pires AS, Gelain DP, Moreira JC, Rabelo LA, Vasconcelos SM, Goulart MO. Characterization of blood oxidative stress in type 2 diabetes mellitus patients: increase in lipid peroxidation and SOD activity. Oxid Med Cell Longev. 2012; 2012:819310.

31. Garcia-Ramirez M, Francisco G, Garcia-Arumi E, Hernandez C, Martinez R, Andreu AL, Simo R. Mitochondrial DNA 
oxidation and manganese superoxide dismutase activity in peripheral blood mononuclear cells from type 2 diabetic patients. Diabetes Metab. 2008; 34:117-124.

32. Chaudhry J, Ghosh NN, Roy K, Chandra R. Antihyperglycemic effect of a new thiazolidinedione analogue and its role in ameliorating oxidative stress in alloxan-induced diabetic rats. Life Sci. 2007; 80:1135-1142.

33. Kinnula VL, Crapo JD. Superoxide dismutases in malignant cells and human tumors. Free Radic Biol Med. 2004; 36:718-744.

34. Toh Y, Kuninaka S, Oshiro T, Ikeda Y, Nakashima H, Baba H, Kohnoe S, Okamura T, Mori M, Sugimachi K. Overexpression of manganese superoxide dismutase mRNA may correlate with aggressiveness in gastric and colorectal adenocarcinomas. Int J Oncol. 2000; 17:107-112.

35. Lewis A, Du J, Liu J, Ritchie JM, Oberley LW, Cullen JJ. Metastatic progression of pancreatic cancer: changes in antioxidant enzymes and cell growth. Clin Exp Metastasis. 2005 ; 22:523-532.

36. Tang H, Dong X, Day RS, Hassan MM, Li D. Antioxidant genes, diabetes and dietary antioxidants in association with risk of pancreatic cancer. Carcinogenesis. 2010; 31:607-613.
37. Oberley LW. Mechanism of the tumor suppressive effect of MnSOD overexpression. Biomed Pharmacother. 2005; 59:143-148.

38. Hempel N, Carrico PM, Melendez JA. Manganese superoxide dismutase (Sod2) and redox-control of signaling events that drive metastasis. Anticancer Agents Med Chem. 2011; 11:191-201.

39. Gumieniczek A. Effect of the new thiazolidinedione-pioglitazone on the development of oxidative stress in liver and kidney of diabetic rabbits. Life Sci. 2003; 74:553-562.

40. Cheng JC, Klausen C, Leung PC. Hydrogen peroxide mediates EGF-induced down-regulation of E-cadherin expression via $\mathrm{p} 38$ MAPK and snail in human ovarian cancer cells. Mol Endocrinol. 2010; 24:1569-1580.

41. Lee KH, Kim SW, Kim JR. Reactive oxygen species regulate urokinase plasminogen activator expression and cell invasion via mitogen-activated protein kinase pathways after treatment with hepatocyte growth factor in stomach cancer cells. J Exp Clin Cancer Res. 2009; 28:73.

42. Livak KJ, Schmittgen TD. Analysis of relative gene expression data using real-time quantitative PCR and the 2(-Delta Delta C(T)) Method. Methods. 2001; 25:402-408. 